\title{
Weight status is associated with cross-sectional trajectories of motor co-ordination across childhood
}

\author{
V. P. Lopes, ${ }^{\star} \dagger$ D. F. Stodden $\neq$ and L. P. Rodrigues ${ }^{\star} \$ \\ ${ }^{*}$ Research Center in Sports Sciences, Health Sciences and Human Development (CIDESD), Bragança, Portugal \\ $\dagger$ Department of Sports Science of Polytechnic Institute of Bragança, Bragança, Portugal \\ $\ddagger$ Department of Physical Education \& Athletic Training, University of South Carolina, Columbia, SC, USA, and \\ §Department of Human Kinetics of Polytechnic Institute of Viana do Castelo, Bragança, Portugal
}

Accepted for publication 10 November 2013

Keywords

body fatness, children,

cross-sectional,

movement behaviour,

physical activity

Correspondence:

Vítor Pires Lopes, Rua

Almada Negreiros 74,

5300-171 Bragança,

Portugal

E-mail:vplopes@ipb.pt

\begin{abstract}
Background Research indicates the development of motor co-ordination (MC) may be an important contributing factor to positive or negative weight trajectories across childhood.

Objectives To analyse cross-sectional associations between $\mathrm{MC}$ and weight status in children (boys $n=3344$ - girls $n=3281$ ), aged 6-11 years and assess overweight/obese risk across different ages. Methods Body mass index (BMI) was calculated [body mass $(\mathrm{kg}) /$ height $\left.\left(\mathrm{m}^{2}\right)\right]$. MC was evaluated using the Körperkoordination Test für Kinder (KTK) and a motor quotient (MQ) was calculated. MQ distribution data were split into tertiles. The effect of age, sex and MQ tertiles on BMI and MC was tested with a factorial ANOVA. A logistic regression also was performed to calculate odd ratios (OR) for being overweight/obese at each age.

Results Children with higher MQ demonstrated lower BMI levels $\left(F_{(2,6224)}=222.09 ; P<0.001\right)$. Differences in BMI among MQ tertiles became larger across age $\left(F_{(10,6224)}=4.53 ; P<0.001\right)$. The OR of being overweight/obese in both sexes within the lowest MQ tertile increased in each age group from 6 to 11 years. Specifically, OR increased from 2.26 to 27.77 and from 1.87 to 6.81 in boys and girls respectively.

Conclusions Children with low levels of MC have a higher risk of being overweight/obese and this risk increases with age.
\end{abstract}

\section{Introduction}

Adiposity and low levels of physical activity (PA) have been associated with risk factors of cardiovascular and metabolic diseases in children (Andersen et al. 2011). Emerging research indicates the development of motor co-ordination (MC) may be an important contributing factor to positive or negative weight trajectories across childhood (D'Hondt et al. 2011; Zhu et al. 2011; Castetbon \& Andreyeva 2012; Lopes et al. 2012a). Recent cross-sectional (D'Hondt et al. 2011; Zhu et al. 2011; Castetbon \& Andreyeva 2012) and longitudinal (Lopes et al. 2012a; D'Hondt et al. 2013) studies demonstrate an inverse relationship between measures of $\mathrm{MC}$ and body composition in both boys and girls across childhood (i.e. 5-12 years) with boys and girls generally demonstrating similar associations across childhood (Lopes et al. 2012a; D'Hondt et al. 2013). It also is important to note that the strength of associations between MC and body weight status and PA generally increase over time (D'Hondt et al. 2011; Lopes et al. 2012b).

Normative data generally indicate that body fatness increases as children age (Rolland-Cachera et al. 1987) and that the prevalence of overweight and obesity in children are increasing (WHO 2007). Similarly, normative data generally indicate children improve their motor skill development across time (Kelso \& Clark 1982; Malina \& Bouchard 1991; Malina 
et al. 2004; Gallahue et al. 2011). Unfortunately, many children demonstrate very low levels of MC by the time they enter school and are labelled 'developmentally delayed' (Goodway et al. 2010). In addition, recent evidence indicates the development of MC depends on the context-specific nature of structured and unstructured PA (i.e. the level and variety of motor skill development experiences), appropriate instruction, as well as the quantity of PA (Gallahue et al. 2011; Logan et al. 2011). Alternatively, Vandorpe and colleagues (2012) found that sport participation, which should inherently involve continued practice involving various aspects of MC, may not affect changes in rates of MC improvement in children between 6 and 9 years of age. Children who participated in sports in this study did have higher initial levels of MC at the start of study, but sport participation did not enhance longitudinal MC development to a greater extent than children who did not participate in sports. Overall, it is important to examine associations between MC and body weight status among children at different ends of their respective population distributions to understand the strength of associations across age. Data such as these may provide a better understanding of the relationships among multiple aspects of children's physical development. While longitudinal data would best demonstrate long-term trajectories of MC and weight status, cross-sectional data also can provide important information on this issue.

It has been suggested that body weight status influences MC (Bürgi et al. 2011). However, the directionality, or causal pathways for the relationship between MC and body weight status may be different and change over time based on a multitude of factors (Stodden et al. 2008). Researchers have speculated that MC may be a causal determinant for the development of adiposity and also PA levels as MC was found to be predictor of adiposity (Lopes et al. 2012a). Thus, an individual's MC level may be an underlying factor promoting either positive or negative trajectories of body weight status, while also acknowledging increasing body weight status also may reciprocally influence further development of MC and PA behaviours. Ultimately, low MC may be viewed as a mechanism promoting an unhealthy weight status across time (Stodden et al. 2008), but an unhealthy weight status (i.e. high adiposity) also may influence future MC development (D'Hondt et al. 2013). Based on this premise, we speculate the strength of association between $\mathrm{MC}$ and weight status will change over time as this recursive relationship may compound over time.

The purpose of this study was to analyse associations between MC and weight status in a large cross-sectional sample of children of both sexes aged 6-11 years. We hypothesized that regardless of sex, the relative risk of being overweight/obese would be different based on the level of MC and that relative risk would increase across age groups.

\section{Material and methods}

\section{Participants}

Data were collected from 6625 children (boys $n=3344$ - girls $n=3281$ ), between 6 and 11 years of age (see Table 1 ). These data were combined from several research projects (Ferreira et al. 2002; Maia et al. 2002; Rodrigues et al. 2006; Martins et al. 2010) conducted by the authors in three regions of Portugal (Azores Islands, north-east and central regions of continental area) between 2003 and 2009. All children were attending public schools that were selected according to the general characteristics of each region. Despite the fact that Azores are an archipelago in Atlantic Ocean, there are no marked differences between the regions in terms of social and economic development (Krueger 2011). Descriptive statistics by age and sex for children in each region are depicted in Tables 2 and 3, respectively, for MC [motor quotient (MQ)] and body mass index (BMI). Although there were some significant differences in $\mathrm{MC}$ and BMI among the three regions, there were no systematic differences among regions in $\mathrm{MC}$ and BMI (Tables $2 \& 3$ ). Thus, the combined results on associations between $\mathrm{MC}$ and BMI are representative of children in the three regions.

School directors were asked to participate in the research and parents and children gave their informed consent. The results of children with any diagnosed physical or mental disability were excluded from the final data set. One author of the present study led the data collection in all regions, thus promoting consistent data collection processes and procedures. In each region, the evaluation team was consistently trained. All measures were assessed in the schools during class time. The children were taken out of their classrooms in small groups to complete the assessments. This study was approved by the ethics committee of Polytechnic Institute of Bragança.

Table 1. Sample characteristics: number of boys and girls by age

\begin{tabular}{cll}
\hline Age & Girls & Boys \\
\hline 6 & 529 & 529 \\
7 & 726 & 773 \\
8 & 759 & 766 \\
9 & 757 & 743 \\
10 & 362 & 390 \\
11 & 148 & 143 \\
\hline
\end{tabular}


Table 2. Descriptive statistics for motor co-ordination (motor quotient) in boys and girls by age in each region

\begin{tabular}{|c|c|c|c|c|c|c|c|}
\hline \multirow[b]{2}{*}{ Age } & & \multicolumn{3}{|l|}{ Girls } & \multicolumn{3}{|l|}{ Boys } \\
\hline & & Azores Islands & Central & North-east & Azores Islands & Central & North-east \\
\hline \multirow[t]{2}{*}{6} & $n$ & 439 & 44 & 46 & 451 & 34 & 44 \\
\hline & & $79.6 \pm 14.0$ & $83.1 \pm 11.6$ & $83.2 \pm 15.3$ & $90.0 \pm 13.0$ & $85.5 \pm 13.7$ & $91.2 \pm 13.3$ \\
\hline \multirow[t]{2}{*}{7} & $n$ & 549 & 105 & 72 & 585 & 120 & 68 \\
\hline & & $81.3 \pm 14.5$ & $82.0 \pm 15.9$ & $85.2 \pm 18.4$ & $89.4 \pm 14.8$ & $87.9 \pm 15.6$ & $89.7 \pm 15.0$ \\
\hline \multirow[t]{2}{*}{8} & $n$ & 573 & 125 & 61 & 574 & 118 & 74 \\
\hline & & $84.2 \pm 14.0$ & $79.9 \pm 16.0$ & $85.4 \pm 17.4^{*}$ & $87.2 \pm 15.8$ & $84.1 \pm 14.9$ & $87.6 \pm 15.4$ \\
\hline \multirow[t]{2}{*}{9} & $n$ & 528 & 115 & 114 & 528 & 110 & 105 \\
\hline & & $78.1 \pm 14.8$ & $74.2 \pm 13.5$ & $82.9 \pm 15.4^{*}$ & $86.7 \pm 14.3$ & $80.5 \pm 14.7$ & $94.3 \pm 12.9^{*}$ \\
\hline \multirow[t]{2}{*}{10} & $n$ & 256 & 9 & 97 & 281 & 14 & 95 \\
\hline & & $76.0 \pm 14.0$ & $71.1 \pm 12.4$ & $82.4 \pm 14.7^{*}$ & $87.5 \pm 14.6$ & $75.9 \pm 9.0$ & $86.3 \pm 16.0^{*}$ \\
\hline \multirow[t]{2}{*}{11} & $n$ & 41 & 0 & 107 & 52 & 0 & 91 \\
\hline & & $77.7 \pm 17.2$ & & $83.9 \pm 13.5^{*}$ & $87.3 \pm 19.5$ & & $87.1 \pm 15.9$ \\
\hline
\end{tabular}

*Significant differences between regions $(P<0.05)$.
Table 3. Descriptive statistics for body mass index in boys and girls by age in each region

\begin{tabular}{|c|c|c|c|c|c|c|c|}
\hline \multirow[b]{2}{*}{ Age } & & \multicolumn{3}{|l|}{ Girls } & \multicolumn{3}{|l|}{ Boys } \\
\hline & & Azores Islands & Central & North-east & Azores Islands & Central & North-east \\
\hline \multirow[t]{2}{*}{6} & $n$ & 439 & 44 & 46 & 451 & 34 & 44 \\
\hline & & $17.2 \pm 2.5$ & $16.1 \pm 3.0$ & $16.3 \pm 2.5^{*}$ & $17.2 \pm 2.9$ & $16.4 \pm 2.6$ & $16.2 \pm 2.7^{*}$ \\
\hline \multirow[t]{2}{*}{7} & $n$ & 549 & 105 & 72 & 585 & 120 & 68 \\
\hline & & $17.6 \pm 3.2$ & $17.3 \pm 2.7$ & $16.7 \pm 2.7$ & $17.6 \pm 3.2$ & $16.8 \pm 2.2$ & $17.1 \pm 2.3^{*}$ \\
\hline \multirow[t]{2}{*}{8} & $n$ & 573 & 125 & 61 & 574 & 118 & 74 \\
\hline & & $18.0 \pm 3.1$ & $17.5 \pm 3.2$ & $17.6 \pm 3.3$ & $18.2 \pm 3.5$ & $17.6 \pm 3.2$ & $18.0 \pm 2.7$ \\
\hline \multirow[t]{2}{*}{9} & $n$ & 528 & 115 & 114 & 528 & 110 & 105 \\
\hline & & $18.7 \pm 3.5$ & $18.3 \pm 3.6$ & $18.3 \pm 3.0$ & $18.7 \pm 4.0$ & $18.1 \pm 3.3$ & $17.8 \pm 2.7^{*}$ \\
\hline \multirow[t]{2}{*}{10} & $n$ & 256 & 9 & 97 & 281 & 14 & 95 \\
\hline & & $18.9 \pm 3.7$ & $18.0 \pm 1.4$ & $18.0 \pm 2.9$ & $18.6 \pm 3.5$ & $17.8 \pm 2.9$ & $19.7 \pm 3.9^{*}$ \\
\hline \multirow[t]{2}{*}{11} & $n$ & 41 & 0 & 107 & 52 & 0 & 91 \\
\hline & & $19.6 \pm 4.1$ & & $19.8 \pm 3.7$ & $19.3 \pm 4.0$ & & $19.5 \pm 3.5$ \\
\hline
\end{tabular}

*Significant differences between regions $(P<0.05)$.

\section{Measures}

Stature and body mass were measured using a stadiometer and a scale according to standardized procedures. Values were recorded to the nearest $0.1 \mathrm{~cm}$ and $100 \mathrm{~g}$ respectively. BMI was calculated as body weight $(\mathrm{kg})$, divided by height $(\mathrm{m})$ squared. Weight status was classified according to International Obesity Task Force (IOTF) cut values for BMI (T. Cole et al. 2000; Cole et al. 2007).

Motor co-ordination was evaluated using the Kiphard-Schilling body co-ordination test, Körperkoordination Test für Kinder (KTK), developed and validated on German children (Kiphard \& Schilling 1974). The KTK was administered and scored according to the manual guidelines. The test protocol consists of four test items: (1) balance - the child walks backward on a balance beam $3 \mathrm{~m}$ in length, but of decreasing widths: $6 \mathrm{~cm}, 4.5 \mathrm{~cm}, 3 \mathrm{~cm}$; (2) jumping laterally - the child makes consecutive jumps from side to side over a small beam $(60 \mathrm{~cm} \times 4 \mathrm{~cm} \times 2 \mathrm{~cm})$ as fast as possible for $15 \mathrm{~s}$; (3) one-legged hopping over a foam obstacle with increasing height in consecutive increments of $5 \mathrm{~cm}$; (4) shifting platforms - moving sideways on wooden boards $(25 \mathrm{~cm} \times 25 \mathrm{~cm}$ $\times 2 \mathrm{~cm}$ supported on four legs $3.7 \mathrm{~cm}$ high) for $20 \mathrm{~s}$. The raw performance of each test item was converted into a 'motor quotient' using normative data tables provided by the manual test battery, which was adjusted for age and sex. A total MQ was calculated by adding the four individual item scores. The psychometric characteristics of the KTK have been documented (Kiphard \& Schilling 1974) with a test-retest reliability coefficient for the raw score on the total test battery of 0.97 , while corresponding coefficients for individual tests range from 0.80 to 0.96 . An initial factor analysis of the four individual tests resulted in a single factor labelled 'gross motor co-ordination'. The percentage of total variance in MC explained by the four tests varies from $81 \%$ at 6 years to $98 \%$ at 9 years. Inter-correlations among the four tests ranged from 0.60 to 0.81 in a reference sample of 1228 children. Both the factor analysis and inter-correlations indicated acceptable construct validity. 


\section{Statistical analysis}

Descriptive statistics (means and standard deviations) were calculated for height, weight, BMI and MQ. A one-way ANOvA was used to analyse the differences between regions in $\mathrm{MC}$ and BMI by age and sex. The MQ data were split into tertiles by each age group and sex, resulting in three categories being used for data analyses: low MQ, average MQ and high MQ. The values of each tertile (cut-off values) are shown in Table 4.

In order to test for the effect of age, sex and MQ levels (tertiles) on BMI variation, a factorial ANOva [age (6) $\times \operatorname{sex}(2)$ $\times$ MQ (3)] was conducted with Scheffe post-hoc tests.

A binary logistic regression was used to assess the risk of being overweight/obese based on a two category BMI level discrimination as the dependent variable and MC tertile as the independent variable. Underweight and normal weight children were collapsed into one category and overweight and obese individuals were joined together into another. As underweight children may demonstrate a lower MQ compared with normal weight children (Yusof et al. 2013), MQ levels between normal weight and underweight were examined in both boys and girls at each age. There were no significant differences in MC levels between normal weight and underweight boys or girls, except in girls at 7 years of age. However, the 7 -year-old underweight girls ( $n=290,4.45 \%$ of the total sample) actually demonstrated a higher MQ than normal weight girls $(P=0.009)$. Odd ratios (OR) were calculated separately for boys and girls within each age group.

\section{Results}

Table 4 provides descriptive statistics (means and standard deviations) for all the variables in the study by sex. Table 5 shows descriptive statistics for MQ in boys and girls by age for each level of MC by tertile level. Table 6 displays the prevalence of each weight status category according to IOTF cut-off values (T. J. Cole et al. 2000; Cole et al. 2007). The overweight/obesity prevalence was high in both boys and girls in all age groups (boys: $15.3-24.5 \%$ for overweight and $6.3-11.5 \%$ for obese; girls: $19.6-26.4 \%$ for overweight and $8-13.4 \%$ for obesity). The prevalence of underweight children (boys and girls) varied between $3.3 \%$ and $8.1 \%$.

ANOvA results for BMI variation revealed significant main effects for $\operatorname{sex}\left(F_{(1,6224)}=16.07 ; P<0.001\right)$, age $\left(F_{(5,6224)}=50.59\right.$; $P<0.001)$ and MQ $\left(F_{(2,6224)}=222.09 ; P<0.001\right)$ and significant interaction effects between age and MQ $\left(F_{(10,6224)}=4.53 ; P<\right.$ 0.001). Post-hoc analyses for age indicated there were significant differences in mean BMI levels between all age groups except

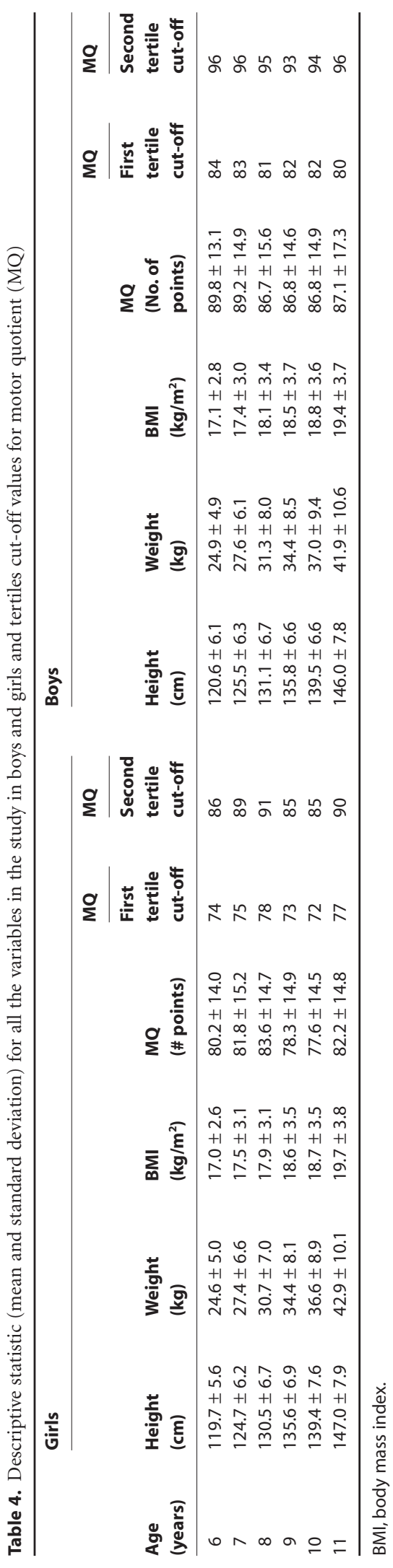


Table 5. Descriptive statistic (mean and standard deviation) for motor quotient in boys and girls by age in each level of motor co-ordination (MC) resulting from dividing the distribution into tertiles

\begin{tabular}{clllllll}
\hline & \multicolumn{2}{l}{ Girls } & \multicolumn{5}{l}{ Boys } \\
\cline { 2 - 3 } Age & MC tertile 1 & MC tertile 2 & MC tertile 3 & & MC tertile 1 & MC tertile 2 & MC tertile 3 \\
\hline 6 & $68.7 \pm 6.9$ & $85.1 \pm 4.0$ & $101.2 \pm 7.4$ & & $72.3 \pm 4.5$ & $85.6 \pm 3.9$ & $102.3 \pm 7.8$ \\
7 & $67.1 \pm 7.8$ & $85.5 \pm 4.0$ & $101.3 \pm 7.5$ & & $69.1 \pm 6.6$ & $85.5 \pm 3.8$ & $103.1 \pm 7.7$ \\
8 & $66.9 \pm 8.2$ & $85.5 \pm 3.8$ & $100.7 \pm 6.3$ & & $67.4 \pm 9.0$ & $86.1 \pm 3.9$ & $101.6 \pm 7.1$ \\
9 & $66.3 \pm 9.5$ & $84.8 \pm 3.9$ & $100.5 \pm 6.7$ & & $68.0 \pm 8.8$ & $86.1 \pm 3.7$ & $101.3 \pm 6.8$ \\
10 & $66.0 \pm 9.5$ & $85.3 \pm 4.1$ & $99.4 \pm 5.7$ & & $67.6 \pm 7.6$ & $85.8 \pm 3.7$ & $101.3 \pm 7.0$ \\
11 & $65.6 \pm 9.5$ & $86.3 \pm 3.8$ & $99.5 \pm 4.9$ & & $65.8 \pm 9.2$ & $85.6 \pm 4.4$ & $104.7 \pm 8.0$ \\
\hline
\end{tabular}

Table 6. Percentage of boys and girls in each category of weight according to International Obesity Task Force (IOTF) cut-off values (T. J. Cole et al. 2000; Cole et al. 2007)

\begin{tabular}{|c|c|c|c|c|c|c|c|c|}
\hline \multirow{2}{*}{$\begin{array}{l}\text { Age } \\
\text { (years) }\end{array}$} & \multicolumn{4}{|l|}{ Girls } & \multicolumn{4}{|l|}{ Boys } \\
\hline & Underweight & Normal weight & Overweight & Obese & Underweight & Normal weight & Overweight & Obese \\
\hline 6 & 4.0 & 60.5 & 23.3 & 12.3 & 5.3 & 66.4 & 17.2 & 11.2 \\
\hline 7 & 3.9 & 62.3 & 20.5 & 13.4 & 3.5 & 70.6 & 15.3 & 10.6 \\
\hline 8 & 4.3 & 63.5 & 20.9 & 11.2 & 3.3 & 67.1 & 18.1 & 11.5 \\
\hline 9 & 5.5 & 58.9 & 25.0 & 10.6 & 4.8 & 66.1 & 18.0 & 11.0 \\
\hline 10 & 4.4 & 68.0 & 19.6 & 8.0 & 3.8 & 68.2 & 19.0 & 9.0 \\
\hline 11 & 8.1 & 56.8 & 26.4 & 8.8 & 4.9 & 64.3 & 24.5 & 6.3 \\
\hline
\end{tabular}

between 6- and 7-year-old groups and between 9- and 10-yearold groups. Average BMI for each age group significantly increased across all age groups, except between 6- and 7-yearold groups and between the 9- and 10-year-old groups. Post-hoc analysis for MQ tertile also showed that differences in mean BMI levels occurred between all MQ tertile groups with a higher MQ associated with lower BMI. Within each age group, children with a higher MQ demonstrated lower BMI levels. More importantly, these results demonstrated that the differences in BMI among MQ tertile groups also became larger across age, with changes being similar in both boys and girls (see Fig. 1). In girls, the mean difference in BMI between first and third MQ tertile group increased from $6.5 \%$ at age 6 to $15.3 \%$ at age 11 . In boys, the mean difference increased from $6.7 \%$ to $21.6 \%$. The differences in BMI between the first and third MQ tertiles increased gradually between 6 and 10 years and then dramatically between 10 and 11 years, but more predominately in boys between ages 10 and 11 years (13.1-15.3\% in girls and $14.4-21.6 \%$ in boys).

Binary logistic regression demonstrated that in each age group in both boys and girls, children in the first (i.e. lowest) MQ distribution tertile had a greater chance of being overweight/obese than children in the second and third tertiles. Those in second tertile also had a greater chance of being overweight/obese than children in the third tertile. The OR values of being overweight/obese for children in the first and second tertiles in both boys and girls increased with age (see Table 7). This increase was dramatic ( $\mathrm{OR}=2.26$ at 6 years to
Table 7. Odds ratios (OR) and $95 \%$ confidence intervals (CI) from logistic regression models predicting overweight/obesity (compared with the third tertile) in boys and girls by age

\begin{tabular}{|c|c|c|c|c|c|}
\hline \multirow{2}{*}{$\begin{array}{l}\text { Age } \\
\text { (years) }\end{array}$} & & \multicolumn{2}{|c|}{ Girls } & \multicolumn{2}{|l|}{ Boys } \\
\hline & & OR & $95 \% \mathrm{Cl}$ & OR & $95 \% \mathrm{Cl}$ \\
\hline \multirow[t]{2}{*}{6} & MC tertile 1 & 1.87 & $1.14-3.08$ & 2.26 & $1.37-3.72$ \\
\hline & MC tertile 2 & 0.97 & $0.56-1.68$ & 1.47 & $0.94-2.29$ \\
\hline \multirow[t]{2}{*}{7} & MC tertile 1 & 3.67 & $2.37-5.69$ & 3.98 & $2.63-6.04$ \\
\hline & MC tertile 2 & 1.69 & $1.06-2.69$ & 1.90 & $1.27-2.84$ \\
\hline \multirow[t]{2}{*}{8} & MC tertile 1 & 3.21 & $2.12-4.86$ & 3.39 & $2.28-5.03$ \\
\hline & MC tertile 2 & 1.71 & $1.13-2.60$ & 2.06 & $1.38-3.08$ \\
\hline \multirow[t]{2}{*}{9} & MC tertile 1 & 5.95 & $3.38-10.47$ & 3.96 & $2.58-6.07$ \\
\hline & MC tertile 2 & 2.65 & $1.47-4.78$ & 2.36 & $1.56-3.56$ \\
\hline \multirow[t]{2}{*}{10} & MC tertile 1 & 4.41 & $1.78-10.91$ & 6.02 & $3.28-11.04$ \\
\hline & MC tertile 2 & 1.67 & $0.642-4.36$ & 2.57 & $1.40-4.69$ \\
\hline \multirow[t]{2}{*}{11} & MC tertile 1 & 6.81 & $2.42-19.19$ & 27.77 & $7.35-104.95$ \\
\hline & MC tertile 2 & 1.82 & $0.63-5.17$ & 7.84 & $2.12-29.00$ \\
\hline
\end{tabular}

$\mathrm{OR}=27.77$ at 11 years) for boys in the first tertile. The increase was not as dramatic ( $\mathrm{OR}=1.87$ at 6 years to $\mathrm{OR}=6.81$ at 11 years) for girls in the first tertile.

\section{Discussion}

The aim of this study was to analyse cross-sectional associations between MC and weight status in children aged 6-11 years. We hypothesized that children with low levels of MC would demonstrate a greater risk of being overweight/obese as compared with children with high MC and that the risk would increase across age-group. 


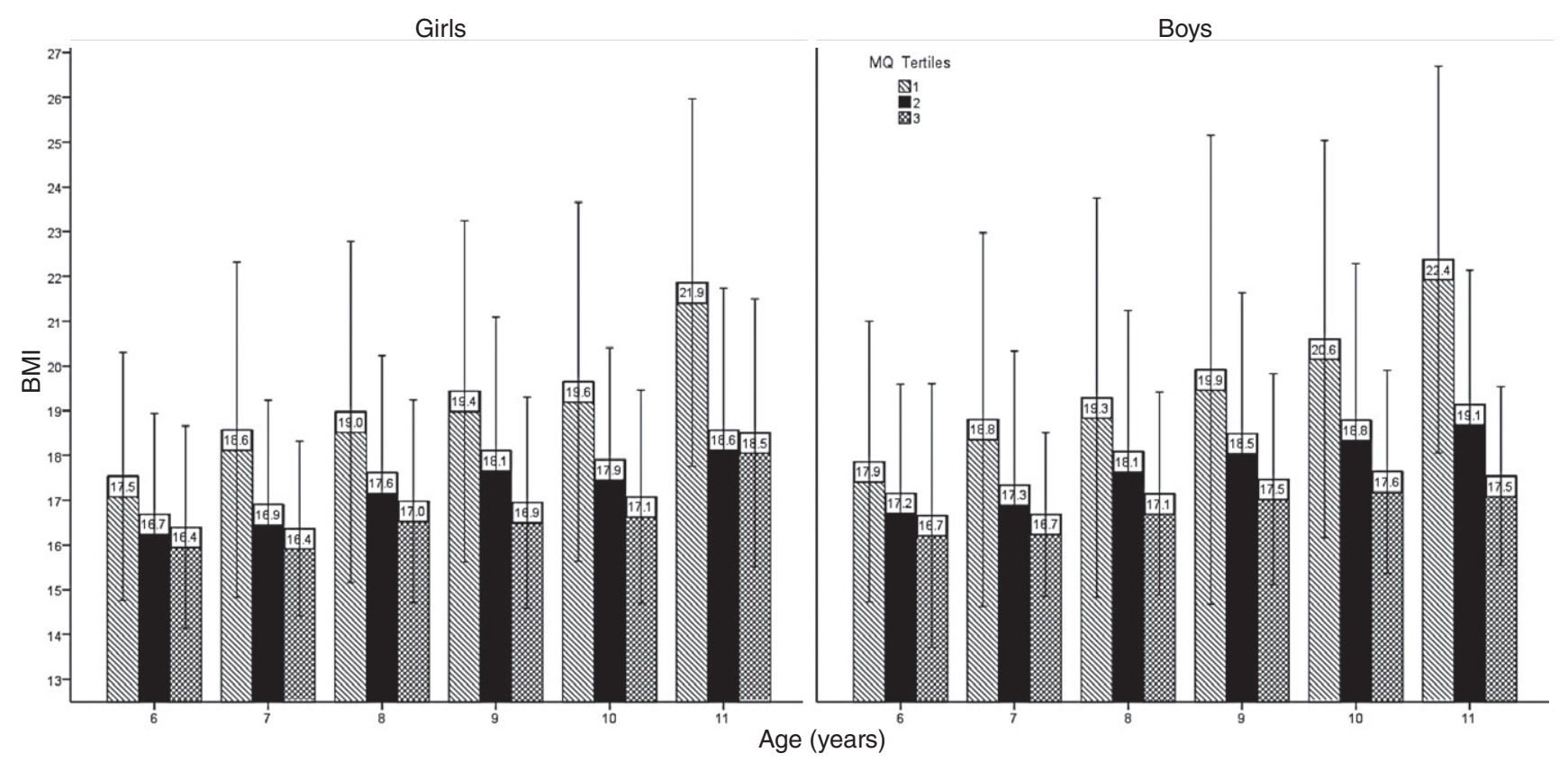

Figure 1. Mean of body mass index (BMI) (with vertical line representing SD) along age according motor quotient (MQ) tertiles groups in girls and boys.

In general, the distribution of MQ data are low in comparison with the reference values of the original KTK. One important idea to consider is the possibility of secular changes that may have occurred since the original norms were derived (approximately 40 years ago). It is quite possible that children's $\mathrm{MC}$ and BMI values are lower in these data based on more recent normative data that show a downward trend in PA and fitness levels, and an increase in BMI levels over the last few decades (Malina 2007; Tomkinson \& Olds 2007). We speculate that MC normative data cut-off values may be different if they were calculated with more recent data.

The results indicated that both boys and girls with low levels of MC had a higher risk of being overweight/obese and that this risk increased across age group. Other studies have indicated that overweight/obese children are at a disadvantage when performing motor skills, specifically for skills where the entire body mass has to be manipulated (Castetbon \& Andreyeva 2012). In general, the tasks in the KTK reflect this idea. The differences between children's BMI levels in the first and third MQ tertiles increased gradually across age between 6 and 10 years and then more dramatically between 10 and 11 years. Similar results were found in a Flemish sample (D'Hondt et al. 2011) where 10- to 12-year-old overweight/obese children showed significantly poorer MC performance compared with the youngest overweight/obese children. In addition, a recent longitudinal investigation (D'Hondt et al. 2013) demonstrated that the development of gross MC over time was strongly related children's weight status. Normal weight children showed more progress in MC than their overweight/obese peers and, consequently, between-group differences in KTK outcomes became more marked over time.

The dramatic increase in the difference between BMI levels for normal weight and overweight/obese children between 10 and 11 years parallel the larger differences in MQ score between those two age groups and, in particular, the increased differences in mean MQ between tertile groups. Specifically, 11-yearold boys' mean MQ difference between first and third tertiles actually increased from 10 years of age (33.7 to 38.9) (see Table 5). The relatively smaller sample size of 11-year-old boys and girls, as compared with the other ages, also may have influenced this dramatic increase in odds ratios. Overall, these results agree with previous cross-sectional and longitudinal studies that demonstrate associations between MC and body weight status increase with age (D'Hondt et al. 2011, 2013; Lopes et al. 2012b)

Growth studies have shown that, in general, there is consistent improvement in children's motor skill development and performance (Kelso \& Clark 1982; Malina et al. 2004) across time. These data describe development with respect to normative growth curves and may be interpreted as universal change 
without addressing inter-individual growth and development differences. The data from this study suggest that normative data may mask differences in MC development (or lack thereof) that may occur in children at the low and high ends of the MC data distribution. As recently noted by D'Hondt and colleagues (2013), normal weight children showed more progress in MC than their overweight/obese peers who had significantly poorer $\mathrm{MC}$, and that differences in MC between BMI groups became greater over time. On the other hand, Lopes and colleagues (2012a) revealed that MC was a predictor of adiposity changes in children from 6 to 10 years of age. Despite of the longitudinal nature of both the D'Hondt et al. and Lopes et al. studies, longitudinal data do not justify promoting either weight status or MC as a direct causative factor primarily responsible for the relationships and why the strength of relationships increased across time. However, Martins and colleagues (2010) indicated that when longitudinal trajectories of MC, PA, cardiorespiratory endurance and weight status were examined across a span of 5 years, the only significant predictor of weight status change was MC.

Based on the data in this study and other recent data (Lopes et al. 2011, 2012a; D'Hondt et al. 2013), when addressing longitudinal growth and development data, researchers should consider the relative level of MC and weight status as longitudinal trajectories of MC and weight status may differ based on early childhood MC and BMI levels. Independent of a causal pathway, emerging cross-sectional and longitudinal data indicate children with low MC have a higher risk for demonstrating an unhealthy weight status. This risk may extend to older ages not only for weight status, but also for PA and health-related physical fitness (Barnett et al. 2009; Stodden et al. 2009, 2013).

As data from this study are cross-sectional, statements alluding to causation are speculative. Long-term experimental studies are needed to verify causative relationships among MC and body weight status. However, the large sample size for most age groups in this study may provide a more robust understanding of the relationship between MC and body composition status during childhood. Unfortunately, no maturation data were collected for this large sample. During puberty, rapid changes in somatic growth with inter individual differences in timing and tempo generally result in changes in muscle mass (boys) and adipose tissue (girls) (Malina et al. 2004). These inter-individual differences in somatic growth could alter relationships between MC and BMI.

Nevertheless, the proposed reciprocal and synergistic relationship between BMI and MC follows a previously published hypothesis (Stodden et al. 2008). This hypothesis may be the most parsimonious and plausible causative pathway for under- standing the relationship between MC and weight status across time with numerous other variables (e.g. PA, fitness level, energy balance, environmental factors) also influencing this relationship. In conclusion, we found significant differences in BMI between children with different MC performance levels, with these differences becoming larger across age groups in both boys and girls. Children with low levels of MC had a higher risk of being overweight/obese and this risk increased with age. Thus, these data demonstrate the need to integrate motor development intervention strategies with children who demonstrate low MC at an early age.

\section{Key messages}

- Different levels of MC are associated to relative risk of being overweight/obese across age and boys and girls generally show similar risk across age.

- The differences in BMI between children with different MC performance levels increase with age in both boys and girls.

- Children with low levels of MC have a higher risk of being overweight/obese and this risk dramatically increases with age.

- Generally assumed improvements in MC may not occur in all children, which demonstrates the need to integrate motor development intervention strategies with children who demonstrate low MC at an early age.

\section{Conflict of interests}

The authors declare that he has no conflict of interest.

\section{References}

Andersen, L. B., Riddoch, C., Kriemler, S. \& Hills, A. (2011) Physical activity and cardiovascular risk factors in children. British Journal of Sports Medicine, 45, 871-876.

Barnett, L. M., Beurden, E. V., Morgan, P. J., Brooks, L. O. \& Beard, J. R. (2009) Childhood motor skill proficiency as a predictor of adolescent physical activity. The Journal of Adolescent Health, 44, 252-259.

Bürgi, F., Meyer, U., Granacher, U., Schindler, C., Marques-Vidal, P., Kriemler, S. \& Puder, J. J. (2011) Relationship of physical activity with motor skills, aerobic fitness and body fat in preschool children: a cross-sectional and longitudinal study (Ballabeina). International Journal of Obesity, 35, 937-944.

Castetbon, K. \& Andreyeva, T. (2012) Obesity and motor skills among 4 to 6-year-old children in the united states: nationally-representative surveys. BMC Pediatrics, 12, 28. 
Cole, T., Bellizzi, M., Flegal, K. \& Dietz, W. (2000) Establishing a standard definition for child overweight and obesity worldwide: international survey. BMJ (Clinical Research Ed.), 320, 1240-1244.

Cole, T. J., Bellizzi, M. C., Flegal, K. M. \& Dietz, W. H. (2000) Establishing a standard definition for child overweight and obesity worldwide: international survey. BMJ (Clinical Research Ed.), 320, 1240-1243.

Cole, T. J., Flegal, K. M., Nicholls, D. \& Jackson, A. A. (2007) Body mass index cut offs to define thinness in children and adolescents: international survey. BMJ (Clinical Research Ed.), 335, 194-197.

D’Hondt, E., Deforche, B., Vaeyens, R., Vandorpe, B., Vandendriessche, J., Pion, J., Philippaerts, R., De Bourdeaudhuij, I. \& Lenoir, M. (2011) Gross motor coordination in relation to weight status and age in 5- to 12-year-old boys and girls: a cross-sectional study. International Journal of Pediatric Obesity, 6, e556-e564.

D’Hondt, E., Deforche, B., Gentier, I., De Bourdeaudhuij, I., Vaeyens, R., Philippaerts, R. \& Lenoir, M. (2013) A longitudinal analysis of gross motor coordination in overweight and obese children versus normal-weight peers. International Journal of Obesity, 37, 61-67.

Ferreira, J. C. V., Marques, A. T. \& Maia, J. (2002) Aptidão física, actividade física e saúde da população escolar do centro da área educativa de Viseu. Um estudo em crianças e jovens de ambos os sexos dos 10 aos 18 anos de idade. Instituto Politécnico de Viseu, Viseu.

Gallahue, D., Ozmun, J. \& Goodway, J. D. (2011) Understanding Motor Development: Infants, Children, Adolescents, Adults. McGraw-Hill Companies, Inc., New York, USA.

Goodway, J. D., Robinson, L. E. \& Crowe, H. (2010) Gender differences in fundamental motor skill development in disadvantaged preschoolers from two geographical regions. Research Quarterly for Exercise and Sport, 81, $17-24$.

Kelso, J. A. S. \& Clark, J. E. (1982) The Development of Movement Control and Co-ordination. John Wiley \& Sons, Nova Iorque, NY, USA.

Kiphard, E. J. \& Schilling, F. (1974) Korper-koordinations-test fur kinder. KTK. Manual. Beltz Test GmbH, Weiheim, Germany.

Krueger, A. (2011) Economy and Finance: Convergence and Disparities in Regional Gross Domestic Product. Eurosat, Brussels, Belgium.

Logan, S. W., Robinson, L. E., Wilson, A. E. \& Lucas, W. A. (2011) Getting the fundamentals of movement: a meta-analysis of the effectiveness of motor skill interventions in children. Child: Care, Health and Development, 38, 305-315.

Lopes, V. P., Rodrigues, L. P., Maia, J. A. R. \& Malina, R. M. (2011) Motor coordination as predictor of physical activity in childhood. Scandinavian Journal of Medicine and Science in Sports, 21, 663-669.

Lopes, V. P., Maia, J. A. R., Rodrigues, L. P. \& Malina, R. M. (2012a) Motor coordination, physical activity and fitness as predictors of longitudinal change in adiposity during childhood. European Journal of Sport Science, 12, 284-391.

Lopes, V. P., Stodden, D. F., Bianchi, M. M., Maia, J. A. R. \& Rodrigues, L. P. (2012b) Correlation between BMI and motor coordination in children. Journal of Science and Medicine in Sport, $15,38-43$.

Maia, J. A. R., Lopes, V. P., Morais, F. P., Silva, R. M. G. \& Seabra, A. (2002) Estudo do crescimento somático, aptidão física, actividade física e capacidade de coordenação corporal de crianças do $1^{\circ} \mathrm{Ciclo}$ do Ensino Básico da Região Autónoma dos Açores. Faculdade de Ciências do Desporto e de Educação Física da Universidade do Porto, Direcção Regional de Educação Física e Desporto da Região Autónoma dos Açores, Direç̧ão Regional de Ciência e Tecnologia da Região Autónoma dos Açores, Porto.

Malina, R. M. (2007) Physical fitness of children and adolescents in the United States: status and secular change. In: Pediatric Fitness Secular Trends and Geographic Variability Medicine Sport Sciences (eds G. R. Tomkinson \& T. S. Olds), pp. 67-90. Karger, Basel.

Malina, R. M. \& Bouchard, C. (1991) Growth Maturation, and Physical Activity. Human Kinetics, Champaign, IL, USA.

Malina, R. M., Bouchard, C. \& Bar-Or, O. (2004) Growth, Maturation and Physical Activity. Human Kintetics, Champaign, IL, USA.

Martins, D., Maia, J., Seabra, A., Garganta, R., Lopes, V., Katzmarzyk, P. \& Beunen, G. (2010) Correlates of changes in BMI of children from the Azores islands. International Journal of Obesity, 34, 1487-1493.

Rodrigues, L., Sá, C., Bezerra, P. \& Saraiva, L. (2006) Estudo Morfofuncional da Criança Vianense. Câmara Municipal de Viana do Castelo, Viana do Castelo, Portugal.

Rolland-Cachera, M.-F., Deheeger, M., Guilloud-Bataille, M., Avons, P., Patois, E. \& Sempé, M. (1987) Tracking the development of adiposity from one moth of age to adulthood. Annals of Human Biology, 14, 219-229.

Stodden, D., Langendorfer, S. \& Roberton, M. A. (2009) The association between motor skill competence and physical fitness in young adults. Research Quarterly for Exercise and Sport, 80, 223-229.

Stodden, D. F., Goodway, J. D., Langendorfer, S. J., Robertson, M. A., Rudisill, M. E., Garcia, C. \& Garcia, L. E. (2008) A developmental perspective on the role of motor skill competence in physical activity: an emergent relationship. Quest (Grand Rapids, Mich.), 60, 290-306.

Stodden, D. F., True, L. K., Langendorfer, S. J. \& Gao, Z. (2013) Associations among selected motor skills and health-related fitness: indirect evidence for Seefeldt's proficiency barrier in young adults? Research Quarterly for Exercise and Sport, 84, 397-403.

Tomkinson, G. R. \& Olds, T. S. (2007) Secular changes in pediatric aerobic fitness test performance: the global picture. In: Pediatric Fitness Secular Trends and Geographic Variability Medicine Sport Sciences (eds G. Tomkinson \& T. Olds), pp. 46-66. Karger, Basel.

Vandorpe, B., Vandendriessche, J., Vaeyens, R., Pion, J., Matthys, S., Lefevre, J., Philippaerts, R. \& Lenoir, M. (2012) Relationship between sports participation and the level of motor coordination 
in childhood: a longitudinal approach. Journal of Science and Medicine in Sport, 15, 220-225.

WHO. (2007) Prevalence of excess body weight and obesity in children and adolescents. From WHO. Available at: http://www.euro.who.int/ en/health-topics/noncommunicable-diseases/obesity/publications/ 2009/2.3-prevalence-of-excess-body-weight-and-obesity-in -children-and-adolescents,-an-enhis-fact-sheet (last accessed 1 February 2010).
Yusof, S. M., Aiman, S., Zawi, M. K., Hasan, H. \& Radzi, A. A. M. (2013) Body Composition Index predict children's motor skills proficiency. World Academy of Science, Engineering and Technology, 79, 1110-1116.

Zhu, Y.-C., Wu, S. K. \& Cairney, J. (2011) Obesity and motor coordination ability in Taiwanese children with and without developmental coordination disorder. Research in Developmental Disabilities, 32, 801-807. 